\title{
В.И. Бажуков
}

\section{РОССИЯ И НАТО: ПАРТНЕРСТВО ИАИ ПРОТИВОСТОЯНИЕ?}

Аннотация. В статье рассматривается взаимодействие между Россией и НАТО после окончания холодной войны, анализируются концептуальные основы современной политики альянса, раскрываются факторы, способствующие и препятствуюшие развитию партнерства между сторонами, показывается влияние расширения НАТО и глобализации ее функций на характер взаимоотношений.

Ключевые слова: партнерство, стратегические конщепции НАТО, иирокий подход к безопасности, глобализация функиий альянса.

Бажуков Владимир Иванович - доктор культурологии,

доцент, профессор факультета глобальных процессов

Московского государственного университета им. М.В. Ломоносова.

E-mail: Bashukovvi@ya.ru

\section{V.I. Bazhukov. Russia and NATO: Partnership or Confrontation?}

Abstract. The article studies the interaction between Russia and NATO after the Cold war, analyzes the conceptual basis of the Alliance modern politics, reveals factors promoting and impeding the development of partnership between the parties, shows how NATO expansion and globalization of its functions influence the relationship.

Keywords: partnership, NATO Strategic Concepts, comprehensive approach to security, globalization of the Alliance functions.

Bazhukov Vladimir Ivanovich - Doctor of Culture Studies,

Associate Professor, Professor of the Department of Global Studies

of Lomonosov Moscow State University. E-mail: bashukovvi@ya.ru

Установка на партнерство России с Североатлантическим союзом возникла и стала проводиться в жизнь в начале 1990 -х годов. С тех пор отношения между сторонами развивались, казалось бы, довольно успешно. В 1991 г. Россия присоединилась к Совету североатлантического сотрудничества (сегодня - Совет евроатлантического партнерства). С 1994 г. Россия участвует 
в программе «Партнерство ради мира» (ПРМ); в 1997 г. был подписан «Основополагающий акт Россия - НАТО о взаимных отношениях, сотрудничестве и безопасности». В 2002 г. принята Римская декларация, в соответствии с которой был образован Совет Россия - НАТО (СРН).

Российская Федерация делала значительные шаги навстречу НАТО и Западу в целом, шла на ряд уступок в военно-политических вопросах. К осени 1994 г. был завершен вывод советских / российских войск из стран Центральной и Восточной Европы. В сентябре 2001 г., когда США подверглись террористическим атакам, российское руководство выразило поддержку американской администрации в ее борьбе с терроризмом. Соединенным Штатам и блоку НАТО оказывалась различная помощь, в том числе был предоставлен транзит через территорию России для военных грузов альянса. Идя на такие уступки, российские политики и общественность ожидали, что со стороны союза и стран Запада будут сделаны встречные шаги, в которых учитывались бы интересы безопасности Российской Федерации. Однако вместо этого военно-политический блок НАТО стал расширяться и продвигаться на Восток, к границам России. Более того, альянс присвоил себе глобальные функции, используя свою военную силу для установления западного лидерства в мире.

С началом кризиса на Украине в 2014 г. руководство НАТО обвинило Россию в совершении агрессии против этой страны и объявило о прекращении военного сотрудничества. В США и в европейских странах НАТО раздувается миф об угрозе со стороны России; в государствах Балтии и Польше происходит наращивание военных сил альянса. В связи с этими процессами возникают вопросы: Что означает партнерство между Россией и НАТО и каковы его перспективы? Как сочетается партнерство с расширением альянса и его военными операциями в различных регионах мира? Надо ли России продолжать сотрудничество с этой организацией или следует отказаться от него? Задачей настоящей статьи является поиск ответов на эти вопросы.

Понятие партнерства в контексте отношений между Россией и НАТО. Понятие «партнерство» в русском языке имеет три значения: 1) взаимоотношения, существующие между партнерами; 2) одна из юридических форм организации совместного предпринимательства (физических или юридических лиц); 3) взаимные контакты, отношения государств, общественных группировок и т.п., основанные на взаимовыгодности и равноправии $[1$, c. 430$]$. Для нас в наибольшей степени подходит третье значение, так как оно непосредственно характеризует отношения между государствами (партнерские) и указывает на их специфику (взаимовыгодность и равноправие).

Понятие «партнерство» широко применяется в документах Североатлантического союза, в соглашениях между этой организацией и отдельными государствами, в том числе между НАТО и Россией. В 1994 г. в рамках союза 
была разработана и принята программа «Партнерство ради мира» (ПРМ), в которой партнерство выступает в качестве основополагающей категории. В программе сформулированы цели, принципы и области сотрудничества в рамках партнерства, определены направления и механизм его реализации. Партнерство для НАТО означает нечто большее, чем просто союз или соглашение о сотрудничестве. Судя по документам и реальной политике альянса, партнерство рассматривается как важный шаг на пути по втягиванию в свой союз новых членов и расширению его влияния на мировой арене. Партнерство означает также стремление руководства НАТО привязать государствапартнеры к своей политике, ограничить их действия жесткими рамками взятых на себя обязательств.

Следует признать, что не все страны-партнеры рассматриваются как кандидаты для вступления в члены союза, а только те, которые сами заявляют о желании вступить в альянс. Россия никогда не ставила вопрос о членстве. Для этого имеются веские основания: национальным интересам России не соответствует политика расширения НАТО и глобализация ее функций, Россия не может поддерживать стремление альянса к установлению западного лидерства на мировой арене. Кроме того, в России не могут не учитывать, что даже намеки о ее членстве в НАТО поставят под угрозу отношения стратегического партнерства с Китаем.

Программа «Партнерство ради мира» включает в себя систему мер и конкретных шагов по сближению стран-партнеров с НАТО; в ней зафиксированы требования к кандидатам, порядок их присоединения к институту партнерства, подробно описаны рабочие документы и планы конкретных действий по укреплению сотрудничества с альянсом. Программой предусмотрено более 20 сфер (вопросов), по которым осуществляется взаимодействие. Эти сферы можно рассматривать как стремление НАТО взять под свой контроль национальную военную политику и стратегию государствпартнеров. Сферы сотрудничества НАТО со странами, входящими в программу ПРМ, можно объединить в четыре большие группы.

Во-первых, сотрудничество по военно-политическим вопросам и миротворческой деятельности. В рамках этого направления выделяются такие сферы взаимодействия, как военная политика и стратегия, демократический контроль над вооруженными силами и оборонными структурами, военное планирование и формирование бюджета, международное сотрудничество в области вооружений, планирование, организация и управление национальными программами военных закупок, миротворческая деятельность и урегулирование кризисных ситуаций.

Во-вторых, программа ПРМ предусматривает сотрудничество по проблемам военно-технического характера. Данное направление охватывает вопросы командования и управления, материально-технического обеспече- 
ния, сферу противовоздушной обороны, управление воздушным движением и контроль за ним. К этому направлению относятся также военные учения, радиоэлектронная борьба, перевозки и транспортировка, системы навигации и опознавания, оперативная совместимость, процедуры и терминология. В эту группу можно включить также медицинские службы, метеорологическое обеспечение, военную географию и различные аспекты стандартизации.

B-третьих, партнерство с НАТО означает сотрудничество по проблемам военного образования и исследований в военной области. Программа предполагает взаимодействие НАТО и стран-партнеров в изучении иностранных языков; планирование, организацию и управление национальными оборонными исследованиями и разработкой технологий.

В-четвертых, в программе ПРМ предусмотрено сотрудничество по линии МЧС, в рамках которого предполагается совместное преодоление последствий стихийных бедствий, проведение учений невоенного характера и связанную с ними деятельность по общей подготовке [11, с. 98-99].

Различные аспекты партнерства между Россией и НАТО получили уточнение и конкретизацию в «Основополагающем акте о взаимных отношениях, сотрудничестве и безопасности между Российской Федерацией и Организацией североатлантического договора», подписанном в 1997 г. В документе определены цели, принципы, области и механизмы взаимоотношений между сторонами. «Россия и НАТО, - подчеркивается в Акте, - не рассматривают друг друга как противников. Общей целью России и НАТО является преодоление остатков прежней конфронтации и соперничества и укрепление взаимного доверия и сотрудничества. Настоящим Актом подтверждается их решимость наполнить конкретным содержанием общее обязательство России и НАТО по созданию стабильной, мирной и неразделенной Европы, единой и свободной, на благо всех ее народов» [7]. Подписание Основополагающего акта рассматривалось как начало «фундаментально новых отношений между Россией и НАТО», как намерение развивать «прочное, стабильное и долговременное партнерство». Стороны признали принципы «неделимости безопасности всех государств евроатлантического сообщества», а также «прочного, стабильного, долговременного и равноправного партнерства и сотрудничества с целью укрепления безопасности и стабильности в Евроатлантическом регионе» [7].

Реальное взаимодействие между Россией и НАТО осуществляется на разных уровнях и по множеству направлений. В рамках Совета Россия НАТО до 2014 г. заседания на уровне послов и военных представителей проводились, как правило, регулярно, не реже одного раза в месяц, на уровне министров иностранных дел, министров обороны и начальников генеральных штабов - 2 раза в год. Кроме того, состоялись три встречи на высшем уровне: в 2002 г. в Риме, в 2008 г. в Бухаресте и в 2010 г. в Лиссабоне. В рамках 
Совета Россия - НАТО было образовано 25 рабочих групп и комитетов по различным вопросам взаимодействия (впоследствии их количество было сокращено).

Основными направлениями сотрудничества являлись борьба с терроризмом и незаконным оборотом наркотиков, кризисное регулирование и отработка вопросов оперативной совместимости войск, противовоздушная оборона и контроль над воздушным пространством, взаимодействие по вопросам противоракетной обороны театра военных действий (ПРО ТВД), противодействие распространению ядерного и других видов оружия массового уничтожения, контроль над обычными вооружениями и военные реформы.

Наиболее успешно развивалось сотрудничество по Афганистану, где 7 октября 2001 г. США вместе со своими союзниками начали военную операцию против движения «Талибан», отказавшегося выдать главаря террористической организации «Аль-Каида» Усаму бен Ладена. Войска НАТО прибыли в Афганистан в составе Международных сил содействия безопасности, образованных по решению Совета Безопасности ООН от 20 декабря 2001 г. (резолюция 1386) «для оказания помощи афганскому Временному органу в обеспечении безопасности в Кабуле и прилегающих к нему районах, с тем чтобы афганский Временный орган, а также персонал Организации Объединенных Наций могли действовать в условиях безопасности» [6].

Совет Россия - НАТО реализует целый ряд проектов по этому направлению: «вертолетный пакет», соглашение о перевозке грузов НАТО в Афганистан и из Афганистана через территорию России, проект по обучению сотрудников правоохранительных органов Афганистана методам борьбы с незаконным оборотом наркотиков. В 2010 г. была одобрена программа по оснащению Афганской армии российскими вертолетами Ми-17, закупки которых велись на основе соглашений между Россией и США. В соответствии с заключенными контрактами, к октябрю 2014 г. Россия поставила Афганистану в общей сложности 63 вертолета на сумму 1,3 млрд долл. США. Кроме того, были решены вопросы по приобретению запчастей для вертолетов, обеспечению лицензионного ремонта и подготовке афганских техников в России. В 2012 г. в Новосибирске начал работать центр по подготовке афганских специалистов [10].

С 2008 по 2015 г. между Россией и НАТО действовало соглашение о транзите грузов для войск США и альянса в Афганистане через территорию России. Россия помогала своим партнерам тем, что предоставляла для перевозок железнодорожный транспорт и транспортную авиацию. На созданном в Ульяновске логистическом пункте грузы переводились с самолетов на железнодорожные платформы. Северный маршрут через территорию России имел для альянса определенные преимущества, так как он связывал Афганистан с морскими портами в странах Прибалтики, что было удобно для евро- 
пейских стран НАТО. В дополнение следует отметить, что на этом маршруте не было тех рисков, которые имелись на южном проходе через территорию Пакистана, где военные караваны нередко подвергались нападениям боевиков и вследствие этого несли потери. Кроме того, транзиту на юге препятствовали противоречия между США и Пакистаном, которые возникли между ними в ходе действий Американской армии. Транзит военных грузов США и НАТО через территорию России был прекращен постановлением Правительства Российской Федерации от 18 мая 2015 г. в связи с завершением мандата Международных сил содействия безопасности в Афганистане [2].

В рамках Совета Россия - НАТО предпринимались попытки решить проблему борьбы с наркотрафиком из Афганистана, который существенно увеличился после начала операции США в этой стране. В декабре 2005 г. на заседании министров иностранных дел стран СРН было принято решение о реализации проекта по обучению работников правоохранительных органов из Афганистана и стран Центральной Азии методам борьбы с незаконным оборотом наркотиков. Проект предусматривал проведение краткосрочных курсов в России и некоторых странах НАТО, а также создание мобильных групп инструкторов, направляемых непосредственно в регион для проведения занятий. Программа курсов предусматривала изучение теории и практики борьбы с наркотрафиком, знакомство с методами досмотра и конфискации, ведения наблюдения и сбора оперативной информации. К 2008 г. обучение на данных курсах прошли 419 сотрудников из Афганистана и стран Центральной Азии $[4$, с. $8-9 ; 5$, с. 7$]$.

Наибольшая активность в области сотрудничества между Россией и НАТО наблюдалась в 2004-2013 гг. В этот период разрабатывались и принимались специальные документы, регулирующие взаимодействие между сторонами в конкретных сферах деятельности, проводились совместные военные учения, отрабатывались вопросы совместимости действий воинских частей и подразделений. Проводились совместные семинары и дискуссии по актуальным вопросам, представлявшим взаимный интерес.

Так, в 2004 г. был принят комплексный План действий Совета Россия НАТО по борьбе с терроризмом. В соответствии с этим планом осуществлялись различные совместные мероприятия: в районе Мурманска были проведены антитеррористические учения «Авария-2004», а в 2006-2007 гг. отдельные корабли Военно-морского флота России приняли участие в контртеррористической операции НАТО «Активные усилия» в Средиземном море.

Сотрудничество между Россией и НАТО в области противоракетной обороны театра военных действий (ПРО ТВД) продолжалось несколько лет и могло бы привести к положительным результатам, если бы не стремление США к созданию глобальной системы ПРО, поддержанное руководством альянса. Представители России и НАТО участвовали в совместной разработке 80 
концепции будущей ПРО ТВД в интересах обеих сторон. В 2004-2006 гг. были проведены командно-штабные учения, направленные на повышение оперативной совместимости российской ПРО и ПРО НАТО. Однако проект по сотрудничеству в области противоракетной обороны не получил развития и был заморожен в связи с тем, что США начали создание районов своей глобальной ПРО на территории Польши и Чехии, а в последующем и в Румынии. Дальнейшее участие России в разработке системы, имеющей антироссийскую направленность, было признано нецелесообразным.

Партнерство между Россией и НАТО еще совсем недавно получало высокие оценки как с российской стороны, так и со стороны Североатлантического альянса. В 2012 г. в Москве была проведена Международная конференция, посвященная 15-летию подписания «Основополагающего акта между Россией и НАТО». Выступая на конференции, ректор Дипломатической академии МИД РФ Е.П. Бажанов отмечал, что «двадцать лет, прошедших после окончания холодной войны, достаточно большой срок, чтобы убедиться в отсутствии у двух бывших антагонистов взаимных агрессивных планов» [9, с. 6]. Похожую мысль высказал и заместитель Генерального секретаря НАТО А. Вершбоу, который, характеризуя отношения между Россией и НАТО, подчеркнул: «Эти отношения были - и остаются сегодня - искренними усилиями наладить стратегическое партнерство между Россией и НАТО. Партнерство, в котором мы укрепляем безопасность вместе друг с другом, а не против друг друга...» [9, с. 34].

Можно приводить и другие примеры и оценки сотрудничества между сторонами. Однако нельзя не признать, что на пути истинного партнерства России и НАТО имеются серьезные препятствия, мешающие равноправному взаимодействию. Между Россией и НАТО сохраняются недоверие и старые стереотипы, в общественном мнении каждой из сторон преобладают негативные оценки действий своего партнера. Как продолжение имеющихся противоречий стало объявленное руководством НАТО 1 апреля 2014 г. в ответ на вхождение Крыма в состав России - решения о приостановлении всякого сотрудничества с Россией.

Факторы, препятствующие равноправному партнерству между Россией и НАТО. Наибольшее беспокойство среди российских политических деятелей и экспертов вызывают расширение НАТО и продвижение ее военной инфраструктуры к границам России, а также расширение функций этой организации. Расширение НАТО началось в 1952 г., когда к ней присоединились Греция и Турция, в 1955 г. членом НАТО стала ФРГ, а в 1982 г. Испания. К окончанию холодной войны в составе НАТО было 16 государств, сегодня их 28, т.е. после роспуска Организации Варшавского договора и распада СССР состав НАТО увеличился на 12 членов. Расширение НАТО после окончания холодной войны происходило тремя волнами: первая волна - 
прием в состав НАТО Венгрии, Польши и Чешской Республики (1999); вторая - присоединение к НАТО семи государств: Болгарии, Латвии, Литвы, Румынии, Словакии, Словении и Эстонии (2004); третья - вступление в состав блока Албании и Хорватии (2009). В 2017 г. ожидается вступление в альянс Черногории.

Расширение организации НАТО и ее продвижение на Восток, бесспорно, является угрозой для национальной безопасности Российской Федерации, что нашло отражение в Военной доктрине РФ и Стратегии национальной безопасности. В результате первой волны расширения, когда к НАТО присоединились Венгрия, Польша и Чешская Республика, военная инфраструктура НАТО продвинулась к границам России на 650-750 км. Североатлантический альянс получил в свое распоряжение большое число военных объектов: около 550 складов боеприпасов, вооружений, горюче-смазочных материалов, 33 военных полигона, 290 аэродромов. НАТО увеличила свою группировку войск на 360 тыс. человек, ее арсенал пополнился 550 боевыми самолетами и вертолетами, 50 боевыми кораблями, примерно 7,5 тыс. танков, БМП и БТР, более 5 тыс. артиллерийских орудий. По оценке В.В. Штоля, использование аэродромов новых членов альянса «позволяет тактической авиации НАТО в той или иной компоновке наносить удары вплоть до Волги. Повысились возможности внезапного первого удара, так как авиация НАТО может подвергать боевому воздействию приграничную полосу Российской Федерации уже через несколько минут после взлета» [13, с. 106-107].

После второй волны расширения НАТО вооруженные силы альянса увеличились еще на 142 тыс. человек, 344 самолета, 1636 танков, более 100 боевых вертолетов и десятки военных кораблей. Североатлантический альянс вышел непосредственно к границам России и союзного государства - Белоруссии. Со вступлением в НАТО стран Балтии геополитическое положение России еще более осложнилось [13, с. 107]. Серьезную угрозу для национальной безопасности России представляют планы США и руководства НАТО по втягиванию в альянс Грузии и Украины.

Еще одной проблемой в отношениях между Россией и НАТО является расширение функций Североатлантического альянса, присвоение им права на одностороннее применение силы, в том числе за пределами территории стран членов блока. В Стратегической концепции НАТО, принятой в ноябре 1991 г., сделаны два вывода, которые необходимо учитывать, если мы хотим понять представления руководства союза о его роли после окончания холодной войны. Первый вывод - это вывод о необходимости сохранения этой организации, несмотря на изменения, которые произошли в странах Центральной и Восточной Европы и в СССР с 1989 г.: «...новая обстановка не меняет цели или функции Союза в плане безопасности, а скорее подчеркивает их неизменную обоснованность». Второй вывод заключался в обосновании нового - широкого - 
подхода к обеспечению безопасности: «...изменение обстановки порождает новые благоприятные возможности, позволяющие Союзу вырабатывать свою стратегию в рамках широкого подхода к безопасности» [3, с. 6].

Как видно из приведенных цитат, в выводах нет даже намека на возможность роспуска НАТО или серьезного ее реформирования, хотя такой шаг, как считали в России, вполне логично напрашивался. Вместо этого был предложен широкий подход к безопасности, который означал более объемный взгляд на понимание рисков и опасностей, угрожающих Североатлантическому союзу. Если в годы холодной войны главной угрозой считалось возможное нападение со стороны СССР и стран Варшавского договора, то теперь, когда такая угроза исчезла, в число рисков и опасностей были включены последствия экономических, социальных и политических трудностей в странах Центральной и Восточной Европы. Также в число новых угроз попали результаты межнациональных конфликтов и территориальных споров, а также процессы, происходящие на постсоветском пространстве.

В концепции утверждается также необходимость учета в обеспечении безопасности членов альянса «глобального контекста». «На интересы Союза в плане безопасности, - подчеркивается в документе, - могут оказать воздействие другие источники риска более широкого характера, включая распространение оружия массового уничтожения, срыв поставок жизненно важных ресурсов, а также террористические акты и диверсии» [3, с. 5]. На все эти риски и опасности альянсом предусматривались соответствующие ответы.

Широкий подход к безопасности НАТО получил подтверждение и более четкое оформление в Стратегической концепции альянса, принятой в апреле 1999 г. на вашингтонском саммите альянса. Стало понятно, что широкий подход к безопасности - это не случайное выражение, а продуманная доктрина, включающая, во-первых, более масштабный взгляд на понимание рисков и опасностей, угрожающих членам альянса, во-вторых, расширение сферы действия блока за пределы Евроатлантического региона. Стратегия НАТО в области безопасности «обогатилась» понятием «операции реагирования на кризис вне статьи 5 Вашингтонского договора» [8, с. 53], которое очень точно раскрывает сущность современной политики альянса. Статья 5 договора об образовании НАТО подразумевает коллективный ответ на вооруженную агрессию в отношении любой страны - участницы альянса.

В новой концепции расширен список угроз безопасности Североатлантического союза, который можно разделить на несколько групп. Первую группу образуют угрозы, связанные с нестабильностью, кризисами и конфликтами «внутри и вокруг Евроатлантического региона», которые могут затронуть интересы безопасности альянса. К этой группе отнесены «серьезные экономические, социальные и политические трудности» в странах указанного региона, «противоборство на этнической и религиозной почве, территориальные 
споры, малоэффективные или неудавшиеся попытки осуществления реформ, нарушения прав человека, распад государств». Во второй группе рассматриваются «мощные ядерные силы за пределами Североатлантического союза», а также распространение оружия массового поражения и средств его доставки. К этой же группе отнесено распространение современных обычных вооружений, технологий их производства и воздействие на информационные системы альянса. В третью группу включены угрозы более широкого характера: «Террористические акты, саботаж, организованная преступность, а также нарушение притока жизненно важных ресурсов, бесконтрольное перемещение больших масс населения, в особенности вследствие вооруженных конфликтов» [8, с. 51].

Исходя из этого, одной из главных задач НАТО концепция провозглашает «предотвращение конфликтов и урегулирование кризисов». В заявлениях союза явно просматривается претензия на то, чтобы заменить собой ООН и Совет Безопасности - притом, что должностные лица альянса постоянно ссылаются на решения ООН и Совета Безопасности ООН. Североатлантический союз присвоил себе миссию «осуществления более широкой задачи укрепления и распространения стабильности». Не случайно в концепции заявлена «возможность проведения операций реагирования на кризисы вне статьи 5 Вашингтонгского договора». Агрессия НАТО на Балканах называется в данном документе «операцией по реагированию на кризис» [8, с. 53].

В 2010 г. в НАТО принята Стратегическая концепция, носящая название «Активное участие, современная оборона». Имеющаяся информация об этой концепции говорит о том, что в ней продолжается линия на участие альянса в операциях за пределами Евроатлантического региона и расширение числа своих членов. К основным задачам блока отнесены коллективная оборона, кризисное регулирование и безопасность на основе сотрудничества. Концепция предполагает активное использование блоком НАТО политических и военных средств, «чтобы помочь регулировать возникающие кризисы, которые могут потенциально затрагивать безопасность Североатлантического союза...» Руководство альянса исходит из того, что «Североатлантический союз подвергается воздействию политических событий и событий в сфере безопасности за пределами его границ, а также может сам воздействовать на эти события» [12]. Как видим, НАТО сохраняет свою приверженность широкому подходу к определению угроз, функций и роли в мировой политике. Такой подход позволяет руководству союза применять силу, вмешиваясь в любой конфликт за пределами территории своих членов в обход решений Совета Безопасности ООН. Концептуальные положения, принятые альянсом, активно реализуются на практике. НАТО участвовала или продолжает участвовать в проведении операций в Югославии, Афганистане, Ираке, Ливии, Сирии. 
В начале 2017 г. в результате избрания на пост президента США Д. Трампа вокруг НАТО возникли дискуссии о ее существовании, назначении, финансировании и других важных вопросах. Дискуссии эти вскоре прекратились. Россия же проявляет готовность к подлинному сотрудничеству и равноправному партнерству.

Подводя итоги, следует предположить, что дальнейшее развитие отношений между Россией и НАТО может проходить по трем основным сценариям.

Оптимистичный сценарий заключается в преодолении негативных тенденций в отношениях между Россией и НАТО и в существенном улучшении их характера. Такой вариант возможен в случае, если альянс откажется от широкого подхода к безопасности и глобализации своих функций, прекратит вмешательство во внутренние дела других государств и насильственное свержение законных правительств, а также ослабит курс на расширение союза и продвижение его на Восток. Важным условием оптимистичного сценария является активное содействие блока НАТО урегулированию конфликта на Украине, оказание помощи правительству этой страны в выполнении Минских соглашений. В списке позитивных факторов могут быть названы также отказ союза от двойных стандартов в сирийском конфликте и прекращение военной активности вблизи границ с Россией. В этом случае можно было бы рассчитывать на серьезные встречные шаги со стороны России.

Такой вариант развития событий является наиболее благоприятным для восстановления и укрепления партнерских отношений между Россией и НАТО. Однако он маловероятен. Начало 2017 г. свидетельствует о том, что никаких явных признаков существенного изменения в политике и стратегии альянса не наблюдается. Россия рассматривается как главная угроза членам НАТО, а в выступлениях лидеров союза звучат призывы вести переговоры с Россией с позиции силы. Продолжается размещение новых натовских сил в Балтийских странах и в Польше, отмечается провокационная военная активность альянса вблизи границ с Россией.

Умеренный сценарий развития отношений между Россией и НАТО заключается в восстановлении того уровня отношений, который существовал до 2014 г., до кризиса на Украине. Этот вариант предполагает сочетание партнерства по одним вопросам с противостоянием по другим. Сотрудничество между Россией и НАТО возможно в тех областях, где интересы сторон совпадают или близки между собой. Россия и НАТО могут успешно взаимодействовать в борьбе против международного терроризма и незаконного оборота наркотиков, в области нераспространения ядерного и других видов оружия массового поражения, а также средств их доставки. Не исключается сотрудничество в противодействии незаконной торговле обычными вооружениями и военной техникой. Большой потенциал имеется в сфере совместного урегулирования международных конфликтов под эгидой $\mathrm{OOH}$; могут быть 
продолжены совместные учения миротворческих сил, учения по спасению экипажей аварийных подводных лодок и др.

Сотрудничество по одним вопросам не исключает наличия противоречий, серьезных дискуссий и даже определенного противостояния по другим, таким как расширение альянса, стремление втянуть в него новые государства, в том числе Грузию и Украину, различие в подходах к урегулированию конфликта в Сирии, продолжение американской программы по созданию районов глобальной системы противоракетной обороны в Румынии и Польше. Такой вариант развития отношений между Россией и НАТО, на наш взгляд, является наиболее вероятным.

Пессимистичный сценарий развития отношений между Россией и НАТО означает скатывание их к конфронтации. Этот вариант возможен в случае, если НАТО предпримет такие действия, которые блокируют возможность партнерства даже на минимальном уровне. К числу наиболее опасных действий альянса могут быть отнесены продолжение курса на достижение мирового лидерства. Опасно также подталкивание правительства Украины к обострению ситуации на Донбассе. Руководство НАТО может выдвинуть России неприемлемые требования, такие как возвращения Крыма, отказ от сотрудничества с Китаем и Ираном, прекращения поддержки правительства Б. Асада в Сирии. Вполне понятно, что список негативных факторов на этом не заканчивается; при желании он может быть расширен.

Подобная политика стран НАТО с высокой вероятностью приведет к блокированию возможностей их партнерства с Россией, будет означать полную деградацию отношений между ними и скатывание их на уровень холодной войны. Исключить такой вариант развития событий нельзя, но есть надежда, что он не реализуется, так как не отвечает ни интересам России, ни Запада.

Возможен ли крупномасштабный вооруженный конфликт между Россией и НАТО? На наш взгляд, такое развитие событий маловероятно. Мы исходим из того, что политические лидеры стран НАТО мыслят и действуют рационально, и человечество не придет к новой мировой войне. Крупномасштабный вооруженный конфликт в Европе был бы по своим последствиям катастрофичным не только для европейских, но и для многих других государств. Сегодня нет такой цели, ради достижения которой можно было бы заплатить столь высокую цену. 


\section{Библиография}

1. Большой академический словарь русского языка / Ред. Л.И. Балахонова. Т. 15. М.; СПб.: Наука, 2011. 610 с.

2. HATO: Альянс не нуждается в афганском транзите // Ведомости. 2015. 20 мая. URL: http:/www.vedomosti.ru/politics/news/2015/05/20/nato-alyans-ne-nuzhdaetsya-v-afganskom-tranzite (Дата обращения: 14.01.2017.)

3. Новая Стратегическая концепция Союза (согласовано главами государств и правительств, участвующих в сессии Совета НАТО в Риме 7-8 ноября 1991 г.) / North Atlantic treaty organization. Bruxelles: Office of inform, [1991]. $18 \mathrm{c}$.

4. Новости НАТО 1/2007. Bruxelles: Office of inform, 2007. $15 \mathrm{c}$.

5. Новости НАТО 1/2008. Bruxelles: Office of inform, 2008. $19 \mathrm{c}$.

6. Организация Объединенных Наций. Совет Безопасности. Резолюция 1386, принятая Советом Безопасности 20 декабря 2001 года // URL: https://documents-dds-ny.un.org/doc/ UNDOC/GEN/N01/708/57/PDF/N0170857.pdf?OpenElement (Дата обращения: 20.11.2016.)

7. Основополагающий акт о взаимных отношениях, сотрудничестве и безопасности между Российской Федерацией и Организацией североатлантического договора // URL: http://www.nato.int/cps/ru/natohq/official_texts_25468.htm (Дата обращения: 30.10.2016.)

8. Путеводитель по материалам саммита НАТО в Вашингтоне 25 апреля 1999 года. Brussels: NATO Office of inform, 1999. $119 \mathrm{c}$.

9. Россия - НАТО: 15 лет на пути к партнерству: Материалы Международной конференции / Под общ. ред. И.А. Сафранчука. М.: Аспект Пресс, 2013. 86 с.

10. Совет Россия - НАТО. Досье // TACC. 2015. 2 декабря. URL: http://tass.ru/info/2492025 (Дата обращения: 20.11.2016.)

11. Справочник НАТО: Юбилейное издание к пятидесятой годовщине НАТО. Брюссель: Отд. информ. и прессы, 1998-1999. 408 с.

12. Стратегическая концепция 2010 г. «Активное участие, современная оборона» // URL: http://www.nato.int/cps/ru/natohq/topics_56626.htm (Дата обращения: 27.11.2016.)

13. Штоль В.В. Армия «нового мирового порядка». М.: ОГИ, 2010. 382 с.

\section{References}

Bol'shoj akademicheskij slovar' russkogo yazyka / Red. L.I. Balachonova. T. 15. Moscow; Saint-Petersburg: Nauka, 2011. 610 p.

NATO: Al'yans ne nuzhdaetsya $\mathrm{v}$ afganskom tranzite // Vedomosti. 2015. 20 maya. URL: http://www.vedomosti.ru/politics/news/2015/05/20/nato-alyans-ne-nuzhdaetsya-v-afganskom-tranzite (Data obrashheniya: 14.01.2017.)

Novaya Strategicheskaya koncepciya Soyuza (Soglasovano glavami gosudarstv i pravitel'stv, uchastvuyushhih v sessii Soveta NATO v Rime 7-8 noyabrya 1991 g.) // North Atlantic treaty organization. Bruxelles: Office of inform, [1991]. $18 \mathrm{p}$.

Novosti NATO 1/2007. Bruxelles: Office of inform, 2007. 15 p.

Novosti NATO 1/2008. Bruxelles: Office of inform, 2008. 19 p.

Organizaciya Ob'edinennyh Nacij. Sovet Bezopasnosti. Rezolyuciya 1386, prinyataya Sovetom Bezopasnosti 20 dekabrya 2001 g. // URL: https://documents-dds-ny.un.org/doc/UNDOC/GEN/N01/ 708/57/PDF/N0170857.pdf?OpenElement (Data obrashheniya: 20.11.2016.)

Osnovopolagayushhij akt o vzaimnyh otnosheniyah, sotrudnichestve i bezopasnosti mezhdu Rossijskoj Federaciej i Organizaciej severoatlanticheskogo dogovora // URL: http://www.nato.int/cps/ ru/natohq/official_texts_25468.htm (Data obrashheniya: 30.10.2016.) 


\section{РОССИЯ И МИР В ХХІ ВЕКЕ}

Putevoditel' po materialam sammita NATO v Washingtone 25 aprelya 1999 goda. Brussels: NATO Office of inform, 1999. $119 \mathrm{p}$.

Rossiya - NATO: 15 let na puti k partnerstvu: materialy Mezhdunarodnoj konferencii // Pod obshh. red. I.A. Safranchuka. Moskow: Aspekt Press, 2013. 86 p.

Shtol' V.V. Armiya «novogo mirovogo poryadka». Moscow: OGI, 2010. 382 p.

Sovet Rossiya - NATO. Dos'e // TASS. 2015. 2 dekabrya. URL: http://tass.ru/info/2492025 (Data obrashheniya: 20.11.2016.)

Spravochnik NATO: yubilejnoe izdanie k pyatidesyatoj godovshhine NATO. Brussels: Otd. Inform. i pressy, 1998-1999. $408 \mathrm{p}$.

Strategicheskaya koncepciya 2010 goda «Aktivnoe uchastie, sovremennaya oborona» // URL: http://www.nato.int/cps/ru/natohq/topics_56626.htm (Data obrashheniya: 27.11.2016.) 